\title{
Comparative study of iron oxide nanoparticles as-prepared and dispersed in Copaiba oil using Mössbauer spectroscopy with low and high velocity resolution
}

\author{
M.I. Oshtrakha,b,*, V. Šepelák ${ }^{\mathrm{c}}$, A.F.R. Rodriguez ${ }^{\mathrm{d}}$, V.A. Semionkin ${ }^{\mathrm{a}, \mathrm{b}}$, M.V. Ushakov $^{\mathrm{a}, \mathrm{b}}$, J.G. Santos $^{\mathrm{e}}$, \\ L.B. Silveira ${ }^{\text {e }}$, E.M. Marmolejo ${ }^{\mathrm{e}}$, M. De Souza Parise $^{\mathrm{f}}$, P.C. Morais ${ }^{\mathrm{f}}$ \\ a Department of Physical Techniques and Devices for Quality Control, Institute of Physics and Technology, Ural Federal University, Ekaterinburg, 620002, Russian Federation \\ ${ }^{\mathrm{b}}$ Department of Experimental Physics, Institute of Physics and Technology, Ural Federal University, Ekaterinburg, 620002, Russian Federation \\ ${ }^{\mathrm{c}}$ Institute of Nanotechnology, Karlsruhe Institute of Technology, Hermann-von-Helmholtz-Platz 1, 76344 Eggenstein-Leopoldshafen, Germany \\ d Universidade Federal do Acre, Rio Branco AC 79900-000, Brazil \\ e Fundação Universidade Federal de Rondònia, Departamento de Física, Ji-Paraná RO 78961-970, Brazil \\ f Universidade de Brasília, Instituto de Física, Núcleo de Física Aplicada, Brasília DF 70910-900, Brazil
}

\section{A R T I C L E I N F O}

\section{Article history:}

Received 26 November 2011

Accepted 22 February 2012

\section{Keywords:}

Mössbauer spectroscopy

Iron oxide nanoparticles

Magnetic fluids

Hyperfine interactions

\begin{abstract}
A B S T R A C T
Iron oxide nanoparticles, probably magnetite, as-prepared and dispersed in Copaiba oil were studied by Mössbauer spectroscopy using two different spectrometers: with a low velocity resolution (512 channels) for measurements at 295 and $21 \mathrm{~K}$ and with a high velocity resolution (4096 channels) for measurements at 295 and $90 \mathrm{~K}$. The fitting of all measured spectra demonstrated that usual models applied to fit Mössbauer spectra of magnetite and maghemite particles were not suitable. Therefore, the recorded spectra were fitted using a large number of spectral components on the basis of better quality of the fit and linearity of differential spectra. The number of components obtained for the better fit appeared to be different for spectra measured with a low and a high velocity resolution. However, these results demonstrated differences of Mössbauer parameters for iron oxide nanoparticles as-prepared and dispersed in Copaiba oil at applied temperatures. The effect of Copaiba oil molecules on Mössbauer parameters may be a result of the interactions of polar molecules such as kaurinic acid with nanoparticles' surface.
\end{abstract}

(C) 2012 Published by Elsevier B.V.

\section{Introduction}

Development of biocompatible magnetic fluids is one of the interesting fields in biomedical research. Magnetic fluids incorporating biocompatible characteristics can be used as contrast agents for magnetic resonance imaging, drug carrier and delivery, local hyperthermia effect, etc. Typical biocompatible magnetic fluids consist of iron-containing magnetic nanoparticles [1-3], thus allowing Mössbauer spectroscopy to be used as an important investigation tool which has been very useful in various biomedical research [4-6]. There are various applications of Mössbauer spectroscopy including the study of magnetic nanoparticles for magnetic fluid development (see, for instance [7]). The Mössbauer data demonstrated important information about magnetic state and size of studied nanoparticles in magnetic fluids. One of the main features of magnetic nanoparticles is related to superparamagnetic behavior of its temperature dependent Mössbauer spectra. The majority of Mössbauer studies were done with a low velocity

\footnotetext{
* Corresponding author.

E-mail address: oshtrakh@mail.utnet.ru (M.I. Oshtrakh).
}

resolution using 512 channels or less for spectra recording. Mössbauer spectra of magnetically ordered iron oxides (magnetite and maghemite) nanoparticles measured with a low velocity resolution were fitted on the base of spinel structural model with tetrahedral (A) and octahedral (B) sites using two magnetic components represented by individual sextets or hyperfine-field distributions mainly (see, for instance [8-13]). However, in some cases Mössbauer spectra were fitted using more magnetic components which were related to the nanoparticle size distribution, non-stoichiometry, Verwey transition for magnetite, etc. (see, for instance [14-18]). It was shown recently that improvement in velocity resolution in Mössbauer spectroscopy leads to new possibilities in the investigation of various samples from biomolecules up to meteorites and nanocomposites [19-23].

Iron oxide nanoparticles dispersed in biocompatible Copaiba oil may be developed as biocompatible magnetic fluids for biomedical aims. In this case it is interesting to analyze the effect of Copaiba oil molecules on magnetic features of nanoparticles. The first preliminary studies of such nanoparticles using Mössbauer spectroscopy with a low [24] and a high [25] velocity resolution demonstrated significant differences in the spectra quality and a number of component for spectra fitting. Therefore, in the present study we 

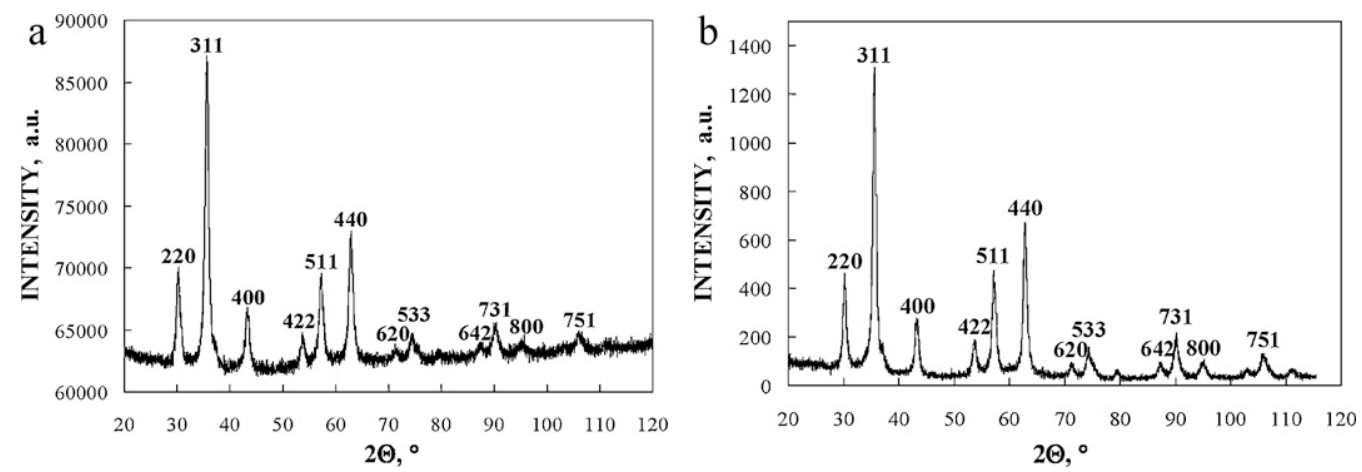

Fig. 1. X-ray diffraction patterns for as-prepared MION (a) and MION dispersed in Copaiba oil (b).

consider the results of comparative investigation of iron oxide, probably magnetite, nanoparticles as-prepared and dispersed in Copaiba oil using Mössbauer spectroscopy with a low and a high velocity resolution at different temperatures.

\section{Materials and methods}

Magnetic iron oxide nanoparticles (MION) probably magnetite $\left(\mathrm{Fe}_{3} \mathrm{O}_{4}\right)$ were synthesized by co-precipitation of a heated mixture of ferrous and ferric chloride aqueous solution with concentrated ammonia $(25 \%, v / v)$, under vigorous stirring. After precipitation of nanosized iron oxide particles and repeated washing using hydrochloric acid a stable sol at $\mathrm{pH} 2$ with nanoparticle volume fraction around $1 \%$ was produced. Copaiba oil was collected from Copaifera tree (Copaifera Langsdorffii Desf.) in the Ji-Paraná region, Rondônia State, Brazil. Copaiba oil dispersed in cyclohexane was then added to the as-produced sol under stirring. The resulting suspension was dried to remove out the organic solvent whereas the precipitated samples (CO-MION) as well as as-prepared MION were used for Mössbauer measurement. Both samples had effective thicknesses of about $15-18 \mathrm{mg} \mathrm{Fe} / \mathrm{cm}^{2}$ for measurement with a high velocity resolution and about $21 \mathrm{mg} \mathrm{Fe} / \mathrm{cm}^{2}$ for measurement with a low velocity resolution.

The phase analysis of MION and CO-MION was made by X-ray powder diffraction (XRD) employing a scanning rate of $0.025^{\circ} / \mathrm{s}$ in $2 \Theta$ range from $20^{\circ}$ to $120^{\circ}$, using a Bruker D8 Advance with $\mathrm{Cu} \mathrm{K} \mathrm{K}_{\alpha}$ radiation. The morphology (shape and size) of MION was studied using an image corrected FEI Titan $80-300$ that provides a point resolution better than $0.1 \mathrm{~nm}$ at $300 \mathrm{kV}$. Images were recorded using a Gatan US1000 slow-scan CCD camera. A selective area electron diffraction (SAED) allowed for structural analysis within MION. Prior to TEM investigations, powders were crushed in a mortar, dispersed in ethanol, and fixed on a copper-supported carbon grid.

Mössbauer spectra were measured using two spectrometers with a low and high velocity resolution. Mössbauer spectra with a low velocity resolution were measured at the Institute of Nanotechnology, Karlsruhe Institute of Technology using computer-controlled Wissel spectrometer with triangular velocity reference signal. Spectra were registered in 512 channels in both direct and reverse motion at 21 and $295 \mathrm{~K}$ using a commercial cryostat (Oxford Instruments). Mössbauer spectra were folded after measurement and statistics from $9.2 \times 10^{5}$ to $1.5 \times 10^{6}$ counts per channel was obtained. Mössbauer spectra with a high velocity resolution were measured at the Institute of Physics and Technology, Ural Federal University using an automated precision Mössbauer spectrometric system on the base of the spectrometer SM-2201 with a high velocity resolution and liquid nitrogen cryostat with moving absorber. Spectrometer SM-2201 operates with the sawtooth shape velocity reference signal and spectra registration in 4096 channels. Details and characteristics of this equipment and the system were described in [26,27]. The Mössbauer spectra were recorded at 295 and $90 \mathrm{~K}$ with statistics from $5 \times 10^{5}$ to $2 \times 10^{6}$ counts per channel. The signal/noise ratio for obtained spectra was in the range from 70 to 110 for the spectra measured with a low velocity resolution and from 43 to 65 for the spectra measured with a high velocity resolution. All spectra were computer fitted with the least squares procedure using UNIVEM-MS program with Lorentzian line shape. Spectral parameters such as isomer shift, $\delta$, quadrupole splitting (quadrupole shift for magnetically split spectra), $\Delta E_{\mathrm{O}}$, magnetic hyperfine field, $H_{\mathrm{eff}}$, line width, $\Gamma$, relative subspectrum area, $S$, and statistical criterion, $\chi^{2}$, were determined. Magnetic sextets were fitted using the sextet peaks areas ratio $S_{1,6}: S_{2,5}: S_{3,4}=3: 2: 1$. Instrumental (systematic) error for the velocity scale or systematic error for the each spectra point was \pm 0.5 channel in the case of measurements using spectrometer SM-2201. It should be noted that this spectrometer characteristics determined an integral velocity error (total mechanical and electronics systematic and random errors) which was several times less than a half of channel value in $\mathrm{mm} / \mathrm{s}$ during spectra measurements using 4096 channels [26]. For the spectra measured using Wissel spectrometer this error was at least twice as larger after folding. Velocity resolution (velocity per one channel) was $\sim 0.04 \mathrm{~mm} / \mathrm{s}$ per channel for 512 channels spectra measured using Wissel spectrometer and $\sim 0.005$ and $\sim 0.006 \mathrm{~mm} / \mathrm{s}$ per channel for 4096 channels spectra measured using spectrometer SM-2201. The relative error for $S$ did not exceed $10 \%$. Criteria of spectra fitting quality were $\chi^{2}$, differential spectrum, and physical meaning of parameters. Values of $\delta$ are given relative to $\alpha$-Fe at $295 \mathrm{~K}$.

\section{Results and discussion}

XRD patterns of MION and CO-MION samples are shown in Fig. 1. These patterns are usual for magnetite or maghemite $\left(\gamma-\mathrm{Fe}_{2} \mathrm{O}_{3}\right)$ which cannot be distinguished by XRD. Both patterns demonstrated the same phase in the studied samples. A representative TEM and high resolution TEM micrographs of MION are shown in Fig. 2a and $b$. It reveals a roughly spherical shape of the nanoparticles with the main size of $8 \mathrm{~nm}$ while there is a small size distribution ranging from 5 to about $18 \mathrm{~nm}$. The high resolution image also shows lattice fringes corresponding to the crystallographic plane (311) $(d=2.532 \AA)$ of the magnetite phase (JCPDS PDF 190629). The lattice fringes cross the whole particle demonstrating its single-crystalline character. It was found that the SAED pattern of the MION consists of both the discrete diffraction spots and Debye-Scherrer rings characteristic of the spinel structure (Fig. 2c). Note that Debye-Scherrer rings and the discrete diffraction spots in the SAED pattern originate from the smaller particles and the well-crystalline larger grains of the MION, respectively.

Mössbauer spectra of MION and CO-MION measured at 295, 90 and $21 \mathrm{~K}$ with a low and a high velocity resolution 

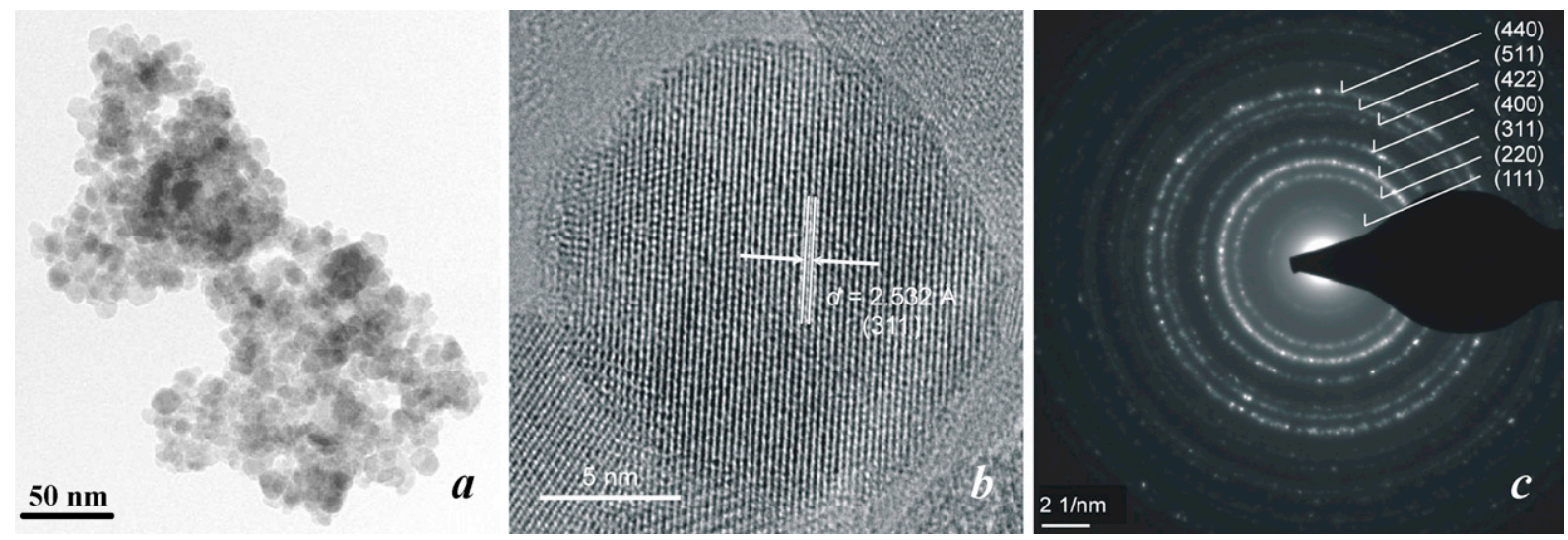

Fig. 2. TEM (a) and high-resolution TEM (b) images of MION and SAED pattern of MION (c).

are shown in Figs. 3-5. These spectra are strongly different from the spectra of bulk or micron-sized magnetite particles which consist of two magnetic sextets related to octahedral and tetrahedral sites (see, for instance [28-30]). However, similar Mössbauer spectra were reported in Ref. [29] for magnetite nanoparticles with average size of about $10 \mathrm{~nm}$ at
296 and $78 \mathrm{~K}$. On the other hand, well known Mössbauer spectra of maghemite measured at the same temperatures (see, for instance $[8,12,31,32]$ ) were also different from the spectra shown in Figs. 3-5. The room temperature spectra of MION and CO-MION measured with a low and a high velocity resolution were similar and show asymmetric broad six lines patterns. However,
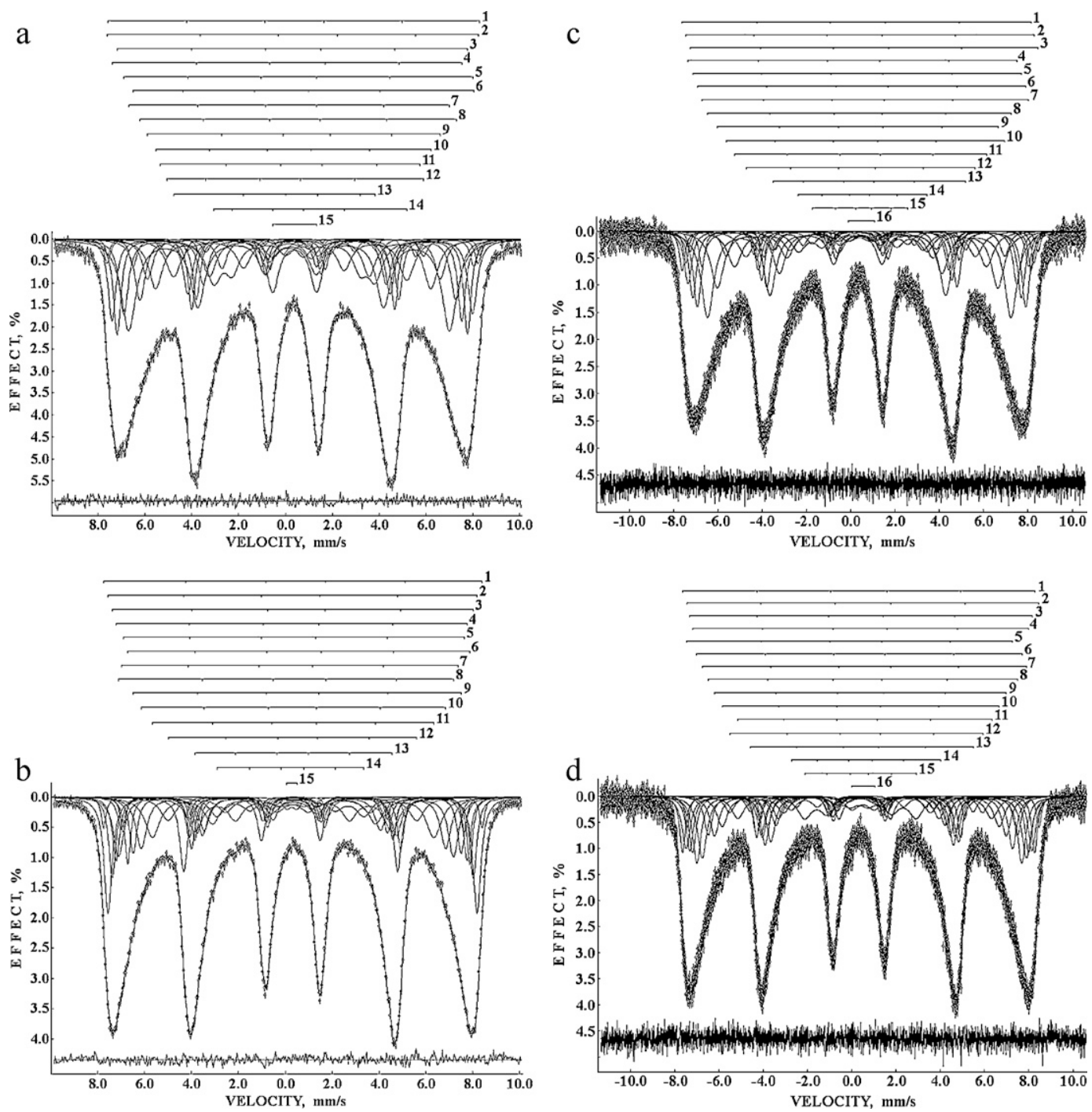

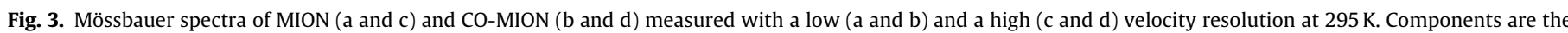
results of the better fit. 

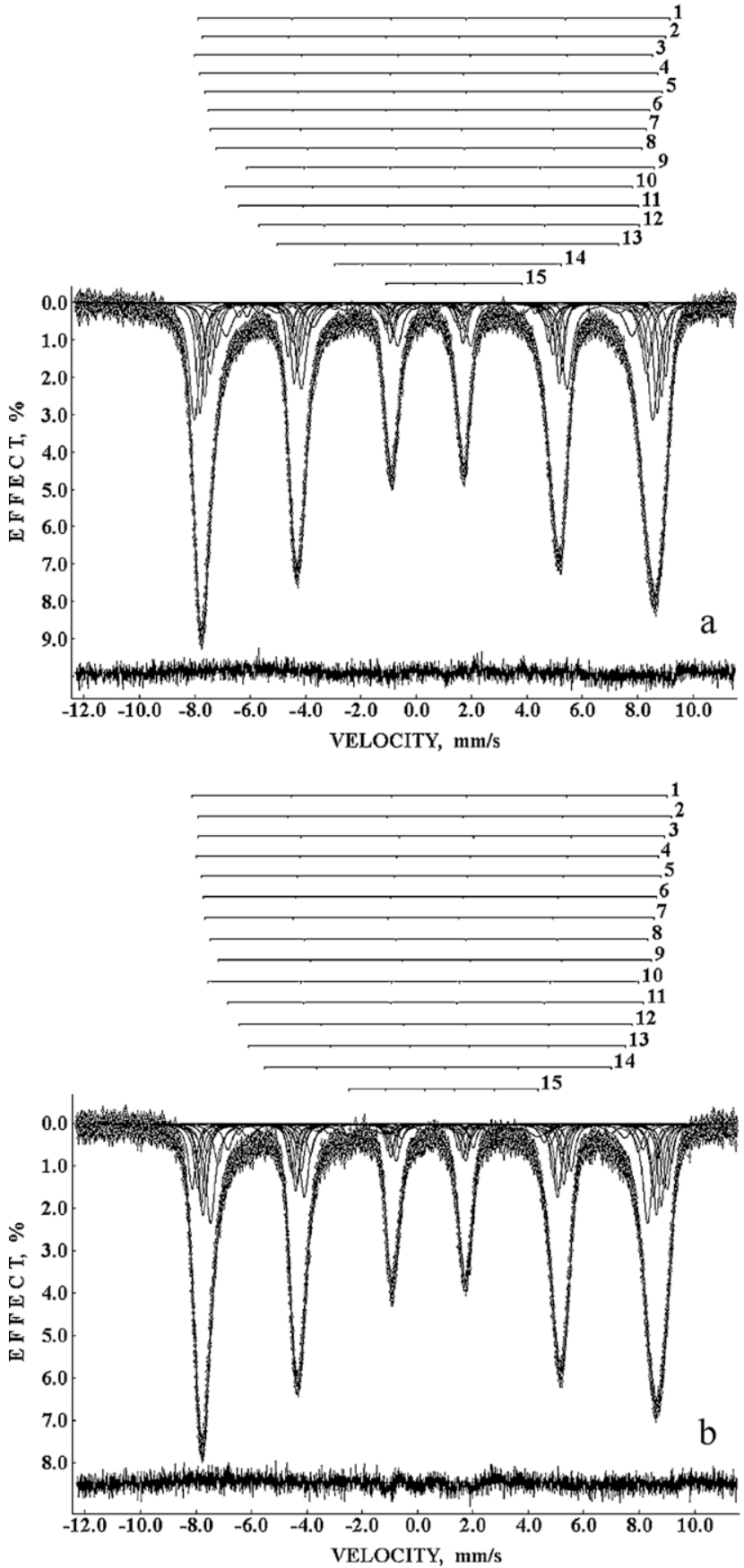
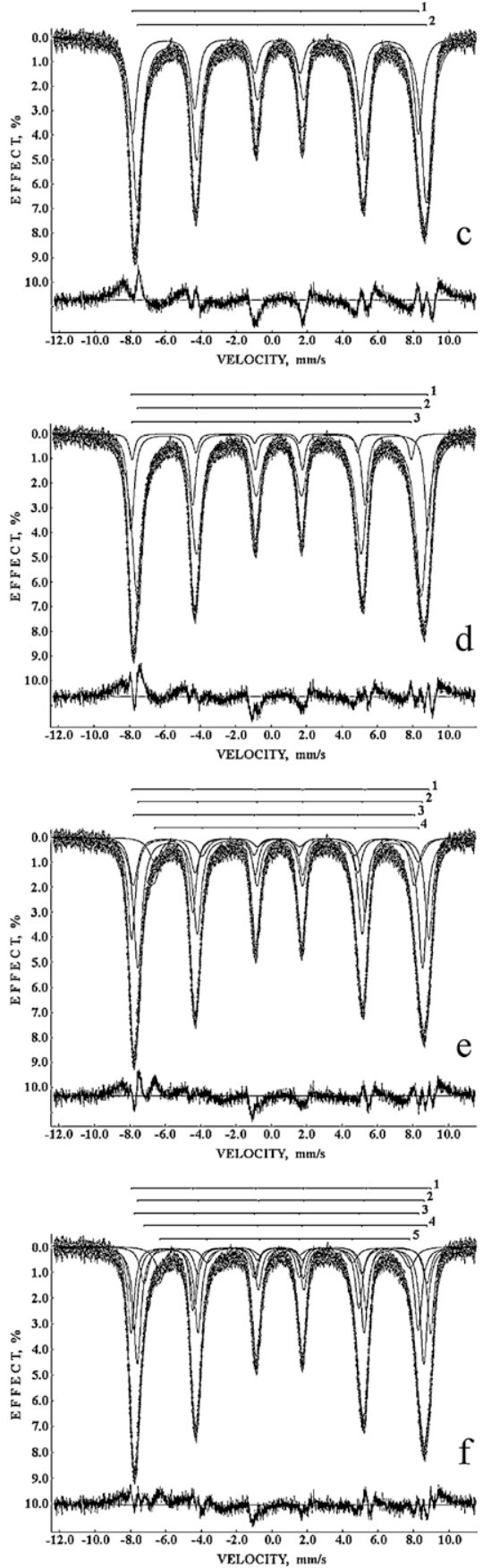

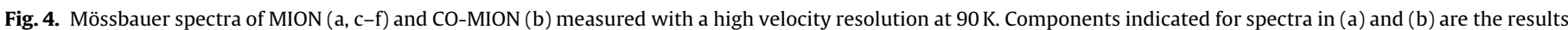
of the better fit while components indicated for the spectrum of MION in (c)-(f) are the results of the fit using 2-5 magnetic sextets, respectively.

MION and CO-MION spectra demonstrated visual differences (for instance, different intensities of the first and the second lines in sextets). In contrast, Mössbauer spectra of MION and CO-MION measured at 90 and $21 \mathrm{~K}$ were similar and show asymmetric six lines patterns with narrower lines without any visual differences. The fit of these spectra was carried out using various numbers of components. It was shown that usual physical model with two magnetic sextets related to the ${ }^{57} \mathrm{Fe}$ nuclei in octahedral and tetrahedral sites was not suitable for such spectra fitting. Moreover, the fit with up to five magnetic sextets was not enough, as can be clearly seen in Fig. 4c-f. Therefore, these spectra were fitted on the basis of the better fit with linear differential spectra, less value of $\chi^{2}$ and physical meaning of parameters. For instance, the Mössbauer spectrum of MION measured at room temperature in 4096 channels was fitted using up to 16 magnetic sextets and 1 weak quadrupole doublet (paramagnetic component) to reach the better fit. The differential spectra remained linearly shaped; in fact with very small changes for fitting models using 11 sextets and more whereas $\chi^{2}$ values varied as follows: $\chi^{2}=3.946$ (10 sextets), $\chi^{2}=3.509$ (11 sextets), $\chi^{2}=3.493$ (12 sextets), $\chi^{2}=3.434$ (13 sextets), $\chi^{2}=3.392$ ( 14 sextets), $\chi^{2}=3.366$ (15 sextets), and $\chi^{2}=3.366$ ( 16 sextets). Standard deviation of $\chi^{2}$ was 0.022 . Therefore, we accepted the result with 15 magnetic sextets and 1 quadrupole doublet. Similar result was obtained during the fit of the Mössbauer spectrum of CO-MION measured at room temperature in 4096 channels. However, Mössbauer spectra of MION and CO-MION measured at room temperature in 512 channels were better fitted using 14 magnetic sextets and 1 weak quadrupole doublet. In spite of the different 

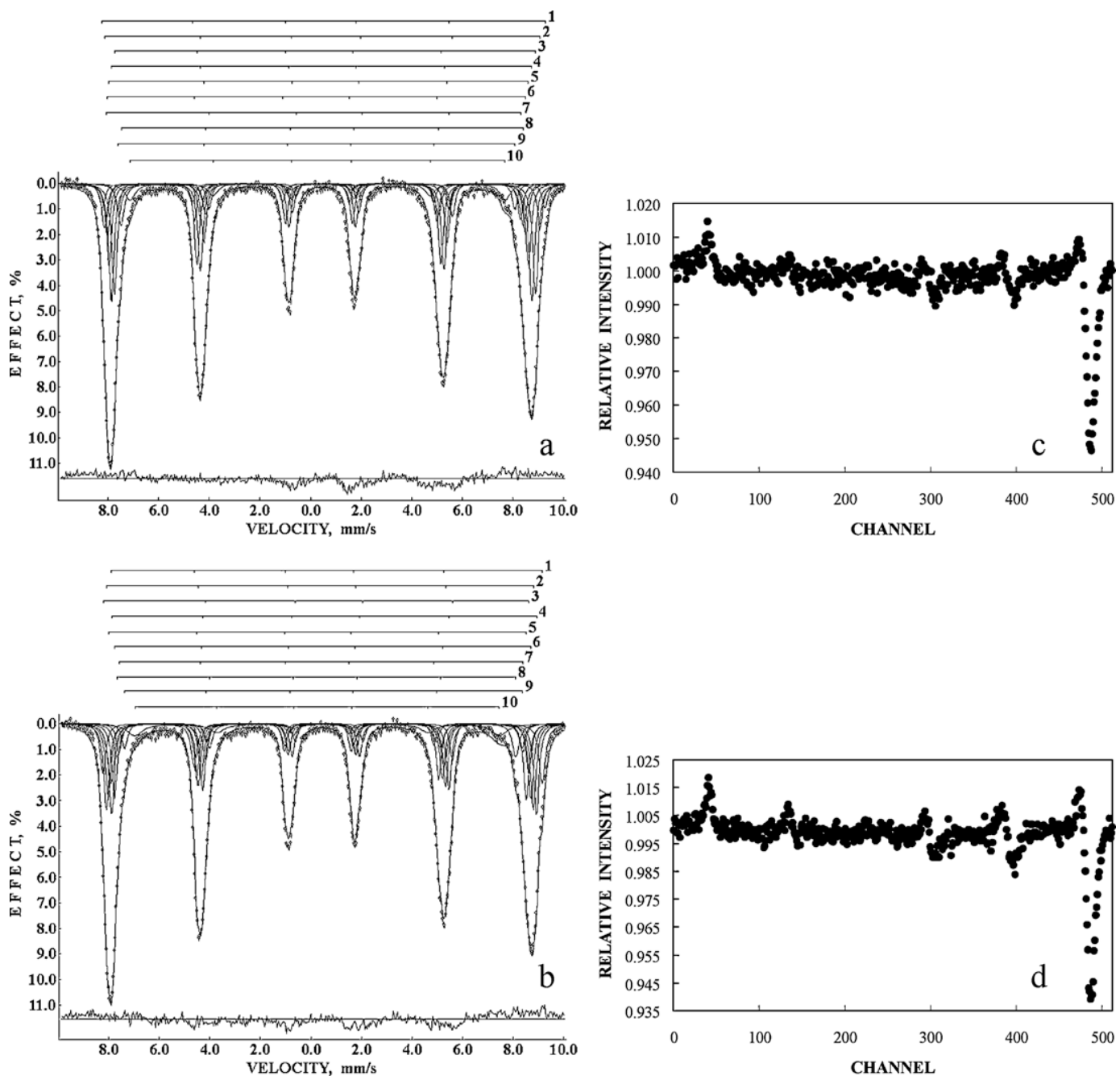

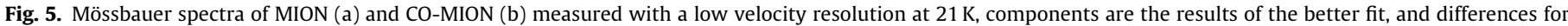
direct and reverse motion Mössbauer spectra of MION (c) and CO-MION (d).

fits and different parameters for correspondent Mössbauer spectra measured with a low and a high velocity resolution, the differences of Mössbauer parameters for MION and CO-MION were observed for both velocity resolutions.

In the case of $90 \mathrm{~K}$ spectrum of MION we observed approximately linear differential spectra for fitting models with 14-15 magnetic sextets and more. The $\chi^{2}$ values varied as follows: $\chi^{2}=1.196$ ( 14 sextets), $\chi^{2}=1.145$ (15 sextets), and $\chi^{2}=1.074$ (16 sextets). The model of fitting using 15 magnetic sextets (Fig. 4a) was accepted in comparison with several other spectra fits in which $\chi^{2}$ values were sometimes smaller while physical meaning of parameters was spurious (for instance, relative area of component was less than $1 \%, \delta$ was larger than $1.2 \mathrm{~mm} / \mathrm{s}$ ). We also observed that in case of a large number of varied parameters (for instance, in the case of 15 magnetic sextets the number of varied parameters is 76) the space of parameters may contain more than one global minimum in addition to local ones. Therefore, it takes a complex analysis of $\chi^{2}$ values, differential spectra and physical meaning of parameters for various fits, especially for fits with the same number of components, in order to select the better fit or develop a new mathematical approach to fit complicated spectra. Thus, we accepted results of the fits using 15 magnetic sextets for spectra of MION and CO-MION measured at $90 \mathrm{~K}$. Mössbauer spectra of MION and CO-MION measured with a low velocity resolution at $21 \mathrm{~K}$ (Fig. 5a and b) were also similar asymmetric six lines patterns that look like spectra measured at $90 \mathrm{~K}$. These spectra may confirm that MION consists of magnetite. The better fit of low temperature spectra was carried out using 10 magnetic sextets only in contrast to $90 \mathrm{~K}$ spectra measured with a high velocity resolution. The reason of different fits results from the larger velocity error in the spectra measured using Wissel spectrometer and different velocity errors on the direct and reverse motion. This is clearly shown by the difference of the spectra measured on the direct and reverse motion (Fig. $5 \mathrm{c}$ and d). However, spectral parameters of MION were different from the correspondent parameters for CO-MION for all Mössbauer measurements.

Unfortunately, the reason of a large number of components in Mössbauer spectra of MION is not clear yet. These magnetic components may be a result of nanoparticle magnetic structure variations from surface to the core region (multi-domain structure) or layers, the presence of A and B sites which may vary in different regions as well as non-stoichiometry and size effects combined with the size dispersity. Nevertheless, we can analyze the obtained results because there is no adequate physical model for spectra fitting yet. Histograms for relative areas of magnetic components obtained from the best fits of Mössbauer spectra of MION and COMION measured with a high velocity resolution at 295 and $90 \mathrm{~K}$ are presented in Fig. 6. The histograms of relative areas of magnetic components appeared to be different for MION and CO-MION at both temperatures. The largest values of $H_{\text {eff }}$ for MION and COMION were respectively of 489 and $494 \mathrm{kOe}$ at $295 \mathrm{~K}$ and 530 and $533 \mathrm{kOe}$ at $90 \mathrm{~K}$. These differences may be related to the effect of 

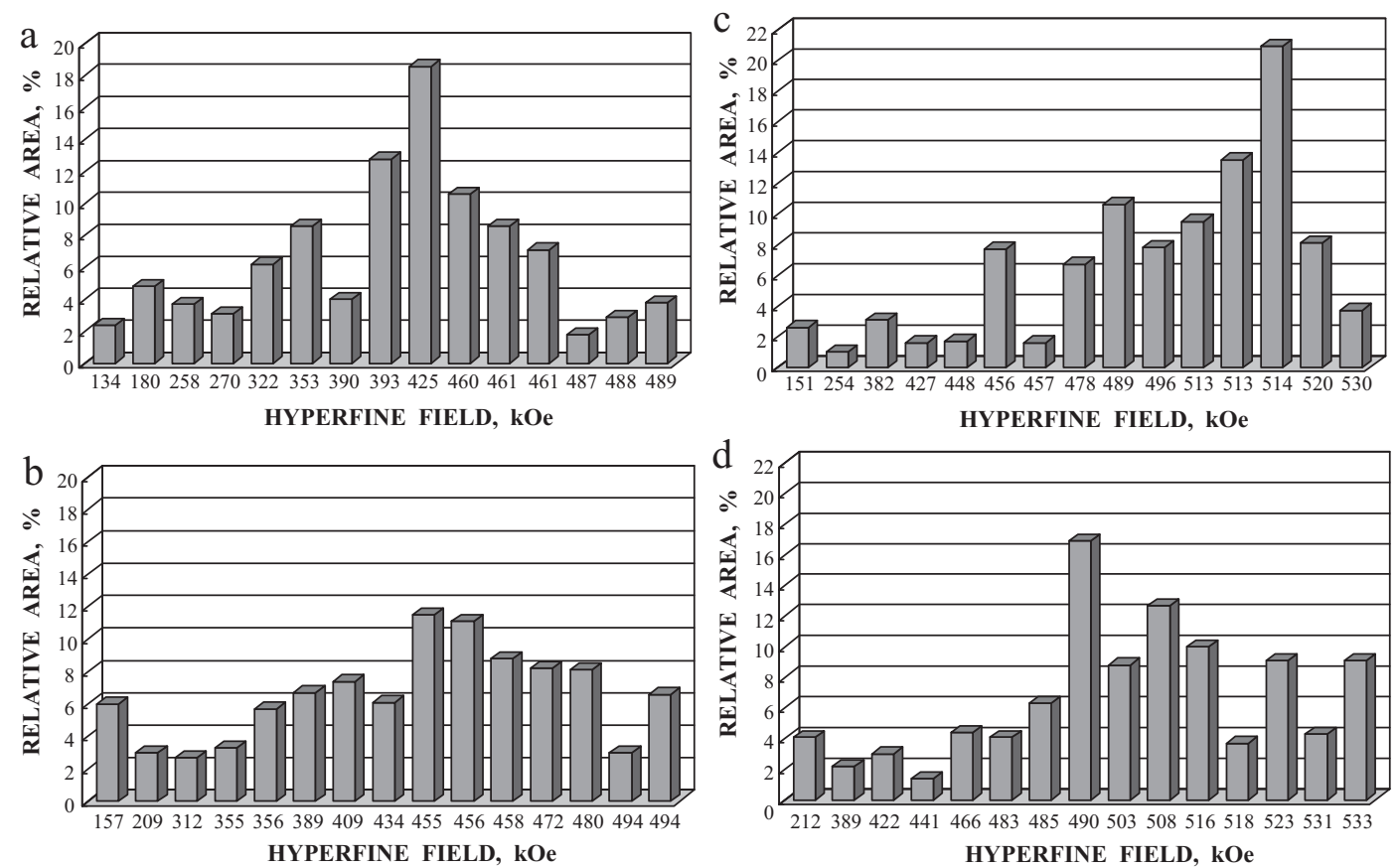

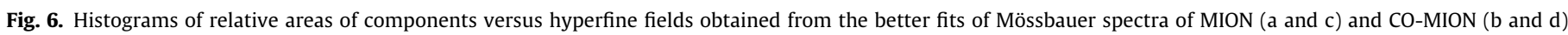
measured in 4096 channels at $T=295 \mathrm{~K}$ (a) and (b) and at $T=90 \mathrm{~K}$ (c) and (d), respectively.

polar molecules in Copaiba oil on the MION surface. It is well known that Copaiba oil contains a large amount of kaurinic acid (chemical structure is shown in Fig. 7a). The kaurinic acid molecule has polar groups which can interact with $\mathrm{Fe}^{3+}$ at the nanoparticle's surface. This may lead to transformation of native MION to kaurinic acid-coated MION like macromolecule hydration in water (see schemes in Fig. 7b and c) after dispersion in Copaiba oil. In this case interaction of polar molecules with MION surface may lead to reduction of spin off-orientations of $\mathrm{Fe}^{3+}$ and consequent increase of internal magnetic field on the ${ }^{57} \mathrm{Fe}$ nuclei. Then surface

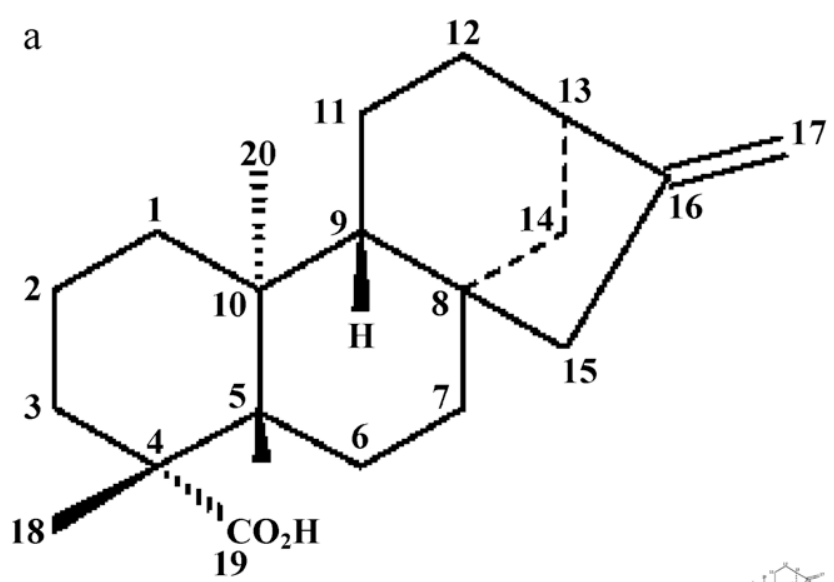

$\mathrm{b}$

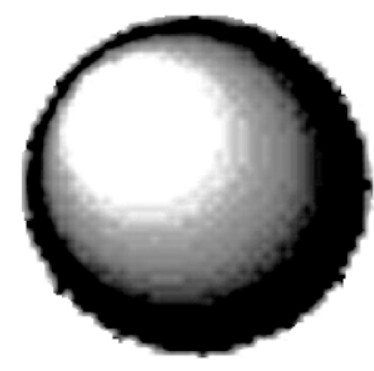

C

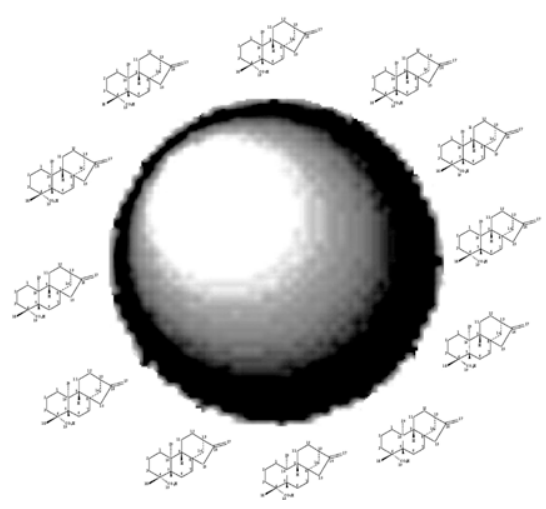

Fig. 7. Chemical structure of kaurinic acid (a), schemes of MION as-prepared (b) and MION surface interaction with kaurinic acid (c). 
changes of the internal magnetic field may affect the ${ }^{57} \mathrm{Fe}$ nuclei in deeper layers or domains in nanoparticles. Thus, the result obtained demonstrates that polar molecules of Copaiba oil may change magnetic properties of MION dispersed in the hosting fluid.

\section{Conclusion}

A comparative study of iron oxide nanoparticles, probably magnetite, as-prepared and dispersed in Copaiba oil using Mössbauer spectroscopy with a low and a high velocity resolution at 295, 90 and $21 \mathrm{~K}$ demonstrated complicated spectra which cannot be fitted well with usual models used for fitting Mössbauer spectra of magnetite and maghemite particles. Therefore, these spectra were fitted using a large number of spectral components on the basis of better quality of fit and linearity of differential spectra. The number of components obtained for the better fit appeared to be different for the spectra measured with a low and a high velocity resolution. In spite of some doubts related to a large number of spectral components, which probably may be related to complicated nanoparticles structure, the results obtained demonstrated interaction of Copaiba oil polar molecules such as kaurinic acid with $\mathrm{Fe}^{3+}$ at the nanoparticle's surface and different Mössbauer parameters for as-prepared and dispersed in Copaiba oil iron oxide nanoparticles at applied temperatures.

\section{Acknowledgements}

The authors wish to thank Dr. S.V. Belikov and Dr. A.S. Yurovskikh for XRD measurement.

\section{References}

[1] Q.A. Pankhurst, J. Connolly, S.K. Jones, J. Dobson, J. Phys. D: Appl. Phys. 36 (2003) R167-R181.

[2] P.C. Morais, R.L. Santos, A.C.M. Pimenta, R.B. Azevedo, E.C.D. Lima, Thin Solid Films 515 (2006) 266

[3] Q.A. Pankhurst, N.K.T. Thanh, S.K. Jones, J. Dobson, J. Phys. D: Appl. Phys. 36 (2009) 224001

[4] M.I. Oshtrakh, J. Mol. Struct. 480-481 (1999) 109-120.

[5] M.I. Oshtrakh, Spectrochim. Acta A: Mol. Biomol. Spectrosc. 60 (2004) 217-234.

[6] M.I. Oshtrakh, Hyperfine Interact. 165 (2005) 313-320.
[7] P.C. Morais, Hyperfine Interact. 181 (2008) 1-12.

[8] G. Salazar-Alvarez, J. Qin, V. Šepelák, I. Bergmann, M. Vasilakaki, K.N. Trohidou, J.D. Ardisson, W.A.A. Macedo, M. Mikhaylova, M. Muhammed, M.D. Baró, J. Nogués, J. Am. Chem. Soc. 130 (2008) 13234-13239.

[9] G.C. Papaefthymiou, E. Devlin, A. Simopoulos, Phys. Rev. B 80 (2009) 024406.

[10] J.C. Aphesteguy, S.E. Jacobo, N.N. Schegoleva, G.V. Kurlyandskaya, J. Alloys Compd. 495 (2010) 509-512.

[11] R.V. Ferreira, I.L.S. Pereira, L.C.D. Cavalcante, L.F. Gamarra, S.M. Carneiro, E. Amaro Jr., J.D. Fabris, R.Z. Domingues, A.L. Andrade, Hyperfine Interact. 195 (2010) 265-274.

[12] J.A.H. Coaquira, C.A. Cardoso, F.Q. Soares, V.K. Garg, A.C. Oliveira, A.F.R. Rodriguez, D. Rabelo, P.C. Morais, Hyperfine Interact. 195 (2010) 149-154.

[13] V. Yathindranath, L. Rebbouh, D.F. Moore, D.W. Miller, J. van Lierop, T. Hegmann, Adv. Funct. Mater. 21 (2011) 1457-1464.

[14] M. Sorescu, A. Grabias, R.A. Brand, J. Voss, D. Tarabasanu-Mihaila, L. Diamandescu, J. Magn. Magn. Mater. 246 (2002) 399-403.

[15] T.J. Daou, G. Pourroy, S. Bégin-Colin, J.M. Grenèche, C. Ulhaq-Bouillet P. Legaré, P. Bernhardt, C. Leuvrey, G. Rogez, Chem. Mater. 18 (2006) 4399-4404.

[16] V.V. Grecu, S. Constantinescu, M.N. Grecu, R. Olar, M. Badea, R. Turcu, Hyperfine Interact. 183 (2008) 205-214.

[17] I. Dézsi, Cs Fetzer, Á. Gombkötő, I. Szűcs, J. Gubicza, T. Ungár, J. Appl. Phys. 103 (2008) 104312.

[18] L.A. Cano, M.V. Cagnoli, S.J. Stewart, E.D. Cabanillas, E.L. Romero, S.G. Marchetti, Hyperfine Interact. 195 (2010) 275-280.

[19] M.I. Oshtrakh, V.A. Semionkin, V.I. Grokhovsky, O.B. Milder, E.G. Novikov, J Radioanal. Nucl. Chem. 279 (2009) 833-846.

[20] M.I. Oshtrakh, V.A. Semionkin, O.B. Milder, E.G. Novikov, J. Mol. Struct. 924-926 (2009) 20-26.

[21] V.I. Grokhovsky, M.I. Oshtrakh, E.V. Petrova, M.Yu. Larionov, K.A. Uymina, V.A Semionkin, Eur. J. Mineral. 21 (2009) 51-63.

[22] M.I. Oshtrakh, V.A. Semionkin, O.B. Milder, I.V. Alenkina, E.G. Novikov, Spectroscopy 24 (2010) 593-599.

[23] M.I. Oshtrakh, I.V. Alenkina, O.B. Milder, V.A. Semionkin, Spectrochim. Acta A Mol Biomol. Spectrosc. 79 (2011) 777-783.

[24] J.G. Santos, L.B. Silveira, Q.S. Ferreira, V.K. Garg, A.C. Oliveira, M.S. Parise, P.C. Morais, J. Phys.: Conf. Series 214 (2010) 012133.

[25] M.I. Oshtrakh, A.F.R. Rodriguez, V.A. Semionkin, J.G. Santos, O.B. Milder, L.B. Silveira, E.M. Marmolejo, M.V.Ushakov, M. de Souza-Parise, P.C. Morais, J. Phys.: Conf. Series 217 (2010) 012018.

[26] M.I. Oshtrakh, V.A. Semionkin, O.B. Milder, E.G. Novikov, J. Radioanal. Nucl. Chem. 281 (2009) 63-67.

[27] V.A. Semionkin, M.I. Oshtrakh, O.B. Milder, E.G. Novikov, Bull. Russ. Acad. Sci.: Phys. 74 (2010) 416-420.

[28] R.N. Panda, N.S. Gajbhiye, G. Balaji, J. Alloys Compd. 326 (2001) 50-53.

[29] G.F. Goya, T.S. Berquo, F.C. Fonseca, M.P. Morales, J. Appl. Phys. 94 (2003) 3520-3528.

[30] J. Wang, M. Yao, G. Xu, P. Cui, J. Zhao, Mater. Chem. Phys. 113 (2009) 6-9.

[31] H.-R. Yin, J.-S. Jiang, J. Mater. Sci. 40 (2005) 3013-3015.

[32] G.C. Papaefthymiou, I. Rabias, M. Fardis, E. Devlin, N. Boukos, D. Tsitrouli, G. Papavassiliou, Hyperfine Interact. 190 (2009) 59-66. 